\title{
Economic burden of age-related macular degeneration in routine clinical practice: the RAMDEBURS study
}

\author{
José M. Ruiz-Moreno (1) Luís Arias • Maximino J. Abraldes • Javier Montero • \\ Patricia Udaondo • The RAMDEBURS study group
}

Received: 9 March 2021 / Accepted: 14 May 2021 / Published online: 10 June 2021

(C) The Author(s) 2021

\begin{abstract}
Purpose To describe and evaluate the main direct health costs, in routine clinical practice, of age-related macular degeneration (AMD) patients, from hospital perspective, in Spain.

Methods Retrospective, multicenter, and observational study conducted on five third-level Spanish hospitals, between December 2018 and December 2019. The study included patients who were diagnosed of AMD before December 2018. Direct healthcare
\end{abstract}

Supplementary Information The online version contains supplementary material available at https://doi.org/10.1007/ s10792-021-01906-x.

\section{J. M. Ruiz-Moreno ( $\square)$}

Puerta de Hierro-Majadahonda University Hospital, Joaquín Rodrigo, 2 Majadahonda, 28222 Madrid, Spain e-mail: josemaria.ruiz@uclm.es

J. M. Ruiz-Moreno

Department of Ophthalmology, Castilla La Mancha

University, Albacete, Spain

J. M. Ruiz-Moreno

Red Temática de Investigación Cooperativa en Salud:

"Prevención, detección precoz, y Tratamiento de La Patología Ocular Prevalente, Degenerativa Y Crónica" (RD16/0008/0021), Spanish Ministry of Health, Instituto de Salud Carlos III, Madrid, Spain

J. M. Ruiz-Moreno

Miranza, Spain costs were obtained from a Spanish database. Study variables included demographic and clinical variables, and resources, such as treatment, diagnostic tests, medical examination, and surgery. Among the 1414 screened AMD patients, 1164 patients were included. In the overall study patients, the total cost was $€ 5,386,511.0$, with a mean cost per patient of $€ 4627.6 \pm 2383.9$. The largest cost items were diagnostic examinations $(€ 2.832 .902,0)$ and vascular endothelial growth factor inhibitors (anti-VEGF) treatment $(€ 2.038 .257,2)$. Bevacizumab was administered to $325(27.9 \%)$ patients, ranibizumab to 328 (28.2\%), and aflibercept to 626 (53.8\%); 115 (10.7\%)

L. Arias

Bellvitge University Hospital, Barcelona, Spain

M. J. Abraldes

Santiago de Compostela University Hospital Complex,

A Coruña, Spain

J. Montero

Río Ortega University Hospital, Valladolid, Spain

P. Udaondo

University and Polytechnic Hospital of La Fé, Valencia, Spain 
patients received two anti-VEGF treatments, while 90 (7.7\%) did not receive any. Over the course of the study, a total of 6,057 anti-VEGF injections were administered, with a mean (95\% confidence interval) of 4.8 (4.4-5.2) injections per patient. Regarding safety, 29 patients experience injection-related adverse events, among them 12 patients had cataract and 11 ones elevated intraocular pressure (IOP). The incidence of endophthalmitis was $0.5 \%$ (6/1164).

Conclusions AMD was associated with considerable healthcare costs for regional healthcare systems. Diagnostic examinations, particularly OCT examinations, and anti-VEGF treatment represented the largest cost items.

Keywords Age-related macular degeneration . Health economics · Economic burden · Vascular endothelial growth factor inhibitors · VEGF

\section{Introduction}

Age-related macular degeneration (AMD) is a prevalent, chronic, and progressive retinal degenerative disease of the macula $[1,2]$.

AMD constitutes one of the leading causes of severe and irreversible visual impairment globally, but most notably in developed countries, among the elderly [3-9]. Its overall prevalence is approximately $8.7 \%$, although variation among different populations is substantial [3-9]. The results of a metaanalysis that included 129,664 subjects showed that the prevalence of AMD ranged from $7.3 \%$ in Asian population to $12.3 \%$ in European ancestry population [5].

Additionally, as the life expectancy is rising up, the importance of AMD increases [10]. It was estimated that the number of people with the disease would be around 196 million in 2020, increasing to 288 million in 2040 [5].

Generally speaking, AMD can be classified as early, intermediate, or late stage [11]. Compared with early AMD, late AMD is far less frequent but most damaging to the sight [11]. According to the latest global estimate of AMD, the prevalence of late AMD in populations of European ancestry was $0.5 \%(95 \%$ confidence interval, CI: 0.26-1.08\%) [5].

The information about the prevalence of AMD in Spain is very limited. Based on the currently available evidence, the estimated prevalence of late AMD (either geographic atrophy or macular neovascularization) ranges between $1.1 \%$ (95\% CI: $1.0-1.2 \%$ ) [7] and $1.9 \%$ [12].

Despite the fact that the introduction of vascular endothelial growth factor inhibitors (anti-VEGF) has supposed a significant advance in therapeutic management of neovascular AMD (NVAMD), none of them cures the disease or reverses its course [13-16]. Additionally, the main drawback of anti-VEGF is their high cost, which suppose a significant burden for health systems, often making such a regimen unaffordable in clinical practice.

According to the results of a metaanalysis, intravitreal aflibercept was associated with a higher overall treatment cost than ranibizumab $(18,187 €$ vs. $17,168 €$, respectively) [17].

Although bevacizumab has been identified as the most cost-effective treatment, its use is "off-label" and not considered the standard of care for NVAMD in Europe (nor it is approved for treating NVAMD by US or European regulatory agencies) [18].

The Spanish Health Systems are public, universal, and mostly free of charge for the patients except for the share of out-of-pocket expenditure, such as transportation-associated costs, meals, glasses and contact lenses prescription, or medicine co-payment, among others [19].

Because AMD treatment entails a significant impact on the Health System budget, it is extremely important to accurately know the cost of these therapeutic strategies.

This study aimed to describe and evaluate the main direct health costs (monetary value), in routine clinical practice, of AMD patients, from hospital perspective, in Spain. Additionally, this study also assessed different clinical and demographic characteristics of the study population.

\section{Methods}

Retrospective, multicenter, and observational study conducted on patients diagnosed of AMD, who were treated in 5 third-level Spanish hospitals, between December 2018 and December 2019.

The study was conducted in accordance with the tenets of the Declaration of Helsinki. The protocol was approved by the ethics committee of Puerta de Hierro- 
Majadahonda University Hospital, which waived the need for informed consent for study participation.

Inclusion/exclusion criteria

This study included patients with a clinical diagnosis of AMD, who were treated in the Ophthalmology department, between December 2018 and December 2019 , in one of the five third-level university hospitals that participated in the study. Patients must have been diagnosed of AMD before December 2018.

Those patients with a clinical diagnosis of AMD who did not require medical interventions, either treatments or visits, during the study follow-up were excluded.

\section{Study centers}

Five third-level hospitals (Listed in the Annex I), representing five Spanish Autonomous Communities (in alphabetical order: Castilla y León; Cataluña; Galicia; Madrid; and Valencian Community), were selected to participate in the study.

Each center was represented by a principal investigator and two sub-investigators from the ophthalmology department.

The Research Group was constituted under the name of Real-World Evidence study of patients with Age-Related Macular Degeneration to evaluate the Economic Burden in Spain (RAMDEBURS).

Costs

Direct healthcare costs were obtained from a Spanish database [20].

The cost of sanitary and consumable supplies, as well as that of antiangiogenic treatments, was provided and averaged by the study centers.

Costs are expressed in euros ( $€)$ and have been updated for the year 2020 [20]. An overview of the unit costs is shown in Annex II.

The overall direct healthcare costs were calculated, as well as the mean cost per patient.

Total costs were estimated considering the unit cost of the different resources and the number of resources consumed by each patient.
Study variables

The information, collected from the medical record, was introduced in an electronic case report form (CRF). For each study participant, the following information was registered:

- Demographic variables: Age, sex, and smoking habit.

- Clinical variables: Type of AMD (exudative, dry, or both); affected area; year of diagnosis; topical prophylactic treatment (before and after intravitreal injections); injection site; type of anesthesia; and injection-related adverse events (cataract, retinal detachment, endophthalmitis, elevated intraocular pressure).

- Resources:

- Treatment: Anti-VEGF administered (type and number of injections), and sanitary and consumable supplies.

- Diagnostic examinations: visual acuity (VA), tonometry, optical coherence tomography (OCT), fluorescein angiography (FA), indocyanine green (ICG), autofluorescence, retinography, fundus (indirect ophthalmoscopy), fundus (biomicroscopy), ultrasonography, and genetic tests.

- Medical examinations: ophthalmology and emergency.

- Surgery: vitrectomy.

Statistical analysis

A standard statistical analysis was performed using the MedCalc ${ }^{\circledR}$ Statistical Software version 19.5.3 (MedCalc Software Ltd, Ostend, Belgium; https://www. medcalc.org; 2020).

Descriptive statistics number (percentage), mean [standard deviation (SD)], mean [95\% confidence interval $(95 \% \mathrm{CI})]$, or median $(95 \% \mathrm{CI})$ were used, as appropriate.

\section{Results}

Among the 1414 screened AMD patients, 1164 patients fulfilled the respective demands of the 


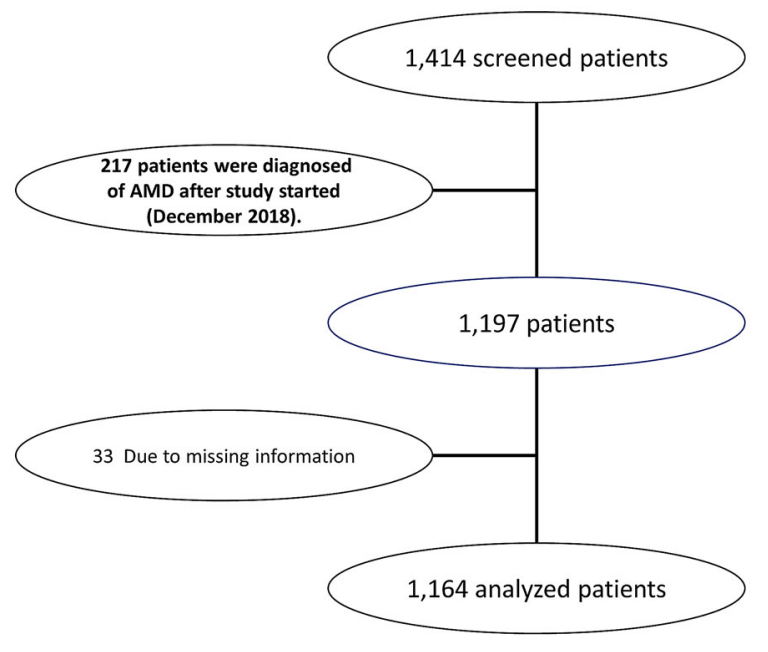

Fig. 1 Study flowchart

inclusion and exclusion criteria. Figure 1 shows the study flowchart.

Mean (95\% CI) age of study sample was 79.8 (79.3-80.2) years, and $689(59.2 \%)$ were women. Table 1 shows the main demographic and clinical characteristics of the study population.

Regarding AMD treatment, bevacizumab was administered to 325 (27.9\%) patients, ranibizumab to $331(28.4 \%)$, and aflibercept to $626(53.8 \%) ; 115$ patients received two anti-VEGF treatments, while 90 did not receive any. Similar proportion of patients received treatment with bevacizumab or ranibizumab $(p=0.8302)$. However, a significant proportion of patients received treatment with aflibercept than with bevacizumab (mean difference 25.9\%, 95\% confidence interval: $21.9-29.6 \%, p<0.0001)$ or ranibizumab (mean difference $25.4 \%$, 95\% confidence interval: $21.5-29.2 \%, p<0.0001)$.

Over the course of the study, a total of 6057 antiVEGF injections were administered, with a mean (95\% CI) of 4.8 (4.4-5.2) injections per patient. Figure 2 shows the distribution of the anti-VEGF treatments administered during the study.

In the overall study patients, the total cost was $€ 5,386,511.0$, with a mean cost per patient of $€ 4627$.6. The largest cost items were diagnostic examinations $(€ 2.832 .902,0)$ and anti-VEGF treatment $(€ 2.038 .257,2)$ (Table 2).

The costs of anti-VEGF treatment supposed $37.8 \%$ of total direct health costs (Fig. 3).
Table 1 Demographic and clinical characteristics

\begin{tabular}{|c|c|}
\hline Variable & $n=1164$ \\
\hline \multicolumn{2}{|l|}{ Age, years } \\
\hline Mean (SD) & $79.8(8.2)$ \\
\hline Range & $44.0-100.0$ \\
\hline \multicolumn{2}{|l|}{$\operatorname{Sex}, n(\%)$} \\
\hline Woman & $689(59.2)$ \\
\hline Man & $475(40.8)$ \\
\hline \multicolumn{2}{|c|}{ Smoking habits, $n(\%)$} \\
\hline Yes & $404(34.7)$ \\
\hline No & $94(8.1)$ \\
\hline Former & $89(7.6)$ \\
\hline Missing data & $577(49.6)$ \\
\hline \multicolumn{2}{|c|}{ Type AMD, $n(\%)$} \\
\hline Exudative & $1012(87.0)$ \\
\hline Atrophic & $12(1.0)$ \\
\hline Both & $140(12.0)$ \\
\hline \multicolumn{2}{|c|}{ Affected eye, $n(\%)$} \\
\hline One eye & $514(44.2)$ \\
\hline Both eyes & $650(55.8)$ \\
\hline \multicolumn{2}{|l|}{ Duration, years } \\
\hline Mean (SD) & $2.7(2.8)$ \\
\hline Range & $0.0-24.0$ \\
\hline \multicolumn{2}{|c|}{ Prophylactic treatment, $n^{a}(\%)$} \\
\hline Before & $133(18.2)$ \\
\hline After & $574(81.2)$ \\
\hline \multicolumn{2}{|l|}{ Anti-VEGF $F^{b, c}(\%)$} \\
\hline Bevacizumab & $325(27.9)$ \\
\hline Ranibizumab & $328(28.2)$ \\
\hline Aflibercept & $626(53.8)$ \\
\hline \multicolumn{2}{|c|}{ Place of injection, $n^{b}(\%)$} \\
\hline Operating room & $134(11.5)$ \\
\hline Clean room & $1027(88.2)$ \\
\hline Office setting & $3(0.3)$ \\
\hline \multicolumn{2}{|l|}{ Anesthesia, $n^{b}(\%)$} \\
\hline Topical & $1070(99.6)$ \\
\hline Subconjunctival & $4(0.4)$ \\
\hline
\end{tabular}

${ }^{\mathrm{a}} n=707$ subjects

${ }^{\mathrm{b}} n=1074$ subjects

${ }^{\mathrm{c}}$ One-hundred and fifteen patients received two anti-VEGF treatments and 90 ones received none

$N$ Number; $S D$ standard deviation; $C I$ confidence interval; $A M D$ age-related macular degeneration; Anti-VEGF vascular endothelial growth factor inhibitors 


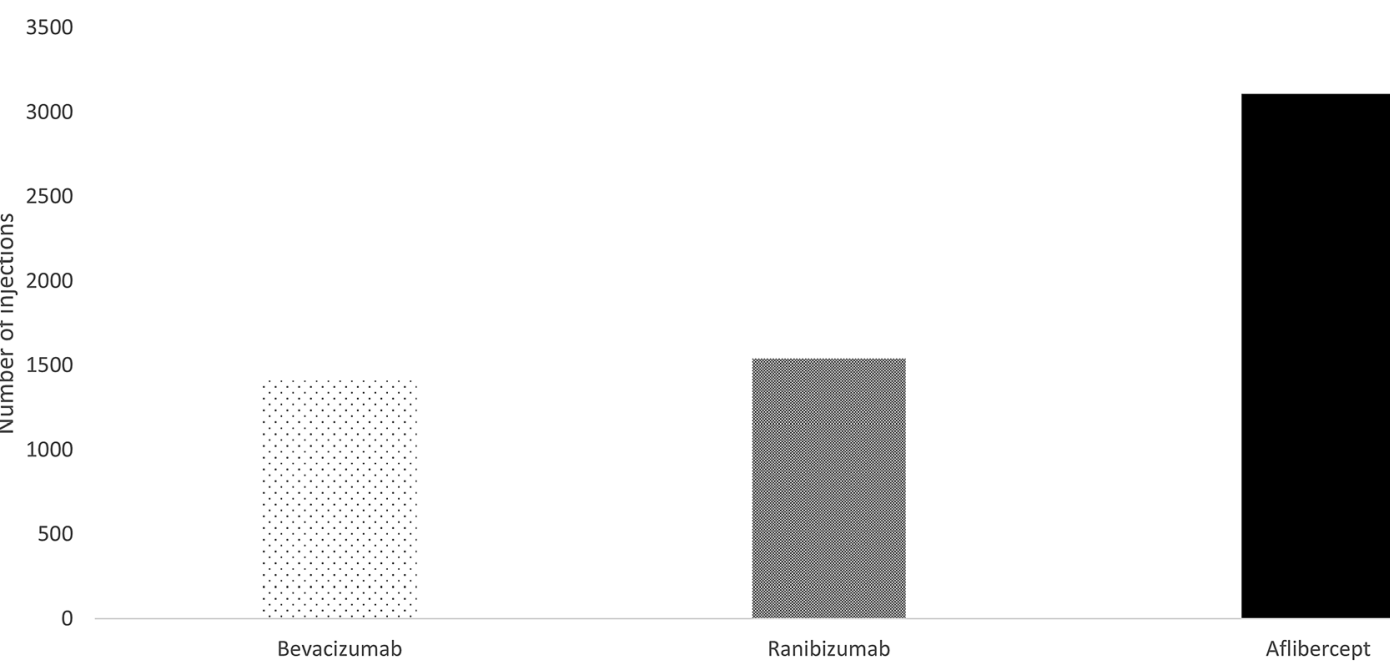

Fig. 2 Number of intravitreal injections according to the vascular endothelial growth factor inhibitor administered

Table 2 Overview of the total costs ${ }^{\mathrm{a}, \mathrm{b}}$

\begin{tabular}{lrrr}
\hline Item & \multicolumn{1}{c}{ Total, $€$} & Mean (SD)/per patient, $€$ & Range, $€$ \\
\hline Diagnostic examinations & $2,832,902.0$ & $2433.8(1615.8)$ & $176.1-11.254 .8$ \\
Medical examinations & $503,706.5$ & $432.7(222.5)$ & $0.0-1659.1$ \\
Surgery & $11,645.4$ & $10.0(152.4)$ & $0.0-2329.1$ \\
Total & $5,386,511.0$ & $4627.6(2383.9)$ & $253.6-15,600.1$
\end{tabular}

${ }^{\mathrm{a}}$ The mean costs were calculated for the total study population $(n=1164$ patients)

${ }^{\mathrm{b}}$ Costs have been updated for the year 2020

$S D$ standard deviation; Anti-VEGF vascular endothelial growth factor inhibitors

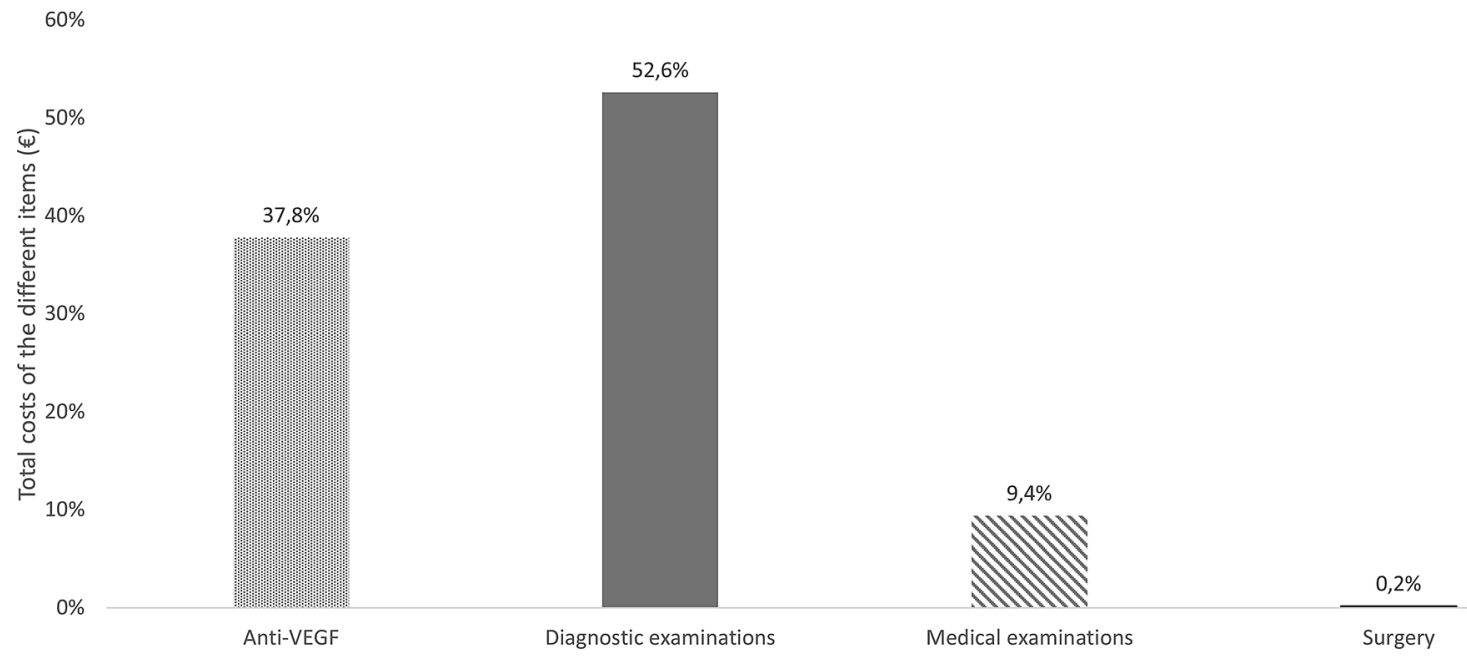

Fig. 3 Overview of costs distribution among the different items (\%) 
Among the 1,074 patients who received anti-VEGF treatment, the mean (SD) cost/per patient was $€ 257.8$ (162.2), €3525.8 (2242.4), and €1274.8 (718.1) for patients treated with bevacizumab, ranibizumab, and aflibercept, respectively.

In these group of patients, the mean cost per patient was $4727.4 \pm 2281.8 €$, which was significantly greater than that observed in the 90 patients who did not receive anti-VEGF therapy (2042.6 $\pm 1307.8 €)$; mean difference: $2684.8 €$; 95\% CI: 2206.3-3163.3€, $p<0.0001$.
Table 3 summarizes the direct costs of the different items. Among diagnostic examinations, OCT $(€ 1,125,541.5)$ and retinography $(€ 775,951.7)$ represented the largest cost items. About examinations costs, ophthalmology examination represented $96.6 \%$ of the total amount.

Throughout the study follow-up, 29 patients experience injection-related adverse events (AEs), among them 12 patients had cataract and 11 ones elevated IOP. The incidence of endophthalmitis was $0.099 \%$ (95\% confidence interval: $0.036-0.215 \%$ ) per intravitreal injection.

Table 3 Overview of breakdown of costs by item ${ }^{1}$

\begin{tabular}{|c|c|c|c|c|c|}
\hline Item & $\mathrm{n}$ & & Total, $€$ & Mean (SD)/per patient, $€$ & Range, $€$ \\
\hline \multirow[t]{4}{*}{ Anti-VEGF } & $1074^{2}$ & Overall & $2,038,257.2$ & $1897.8(1866.1)$ & $0.0-11,271.5$ \\
\hline & 325 & Bevacizumab & $83,796.3$ & $257.8(162.2)$ & 59.4-950.9 \\
\hline & 328 & Ranibizumab & $1,156,450,8$ & $3525.8(2242.4)$ & $751.4-11,271.5$ \\
\hline & 626 & Aflibercept & $798,010.1$ & $1274.8(718.1)$ & $256.8-4108.2$ \\
\hline \multirow[t]{15}{*}{ Diagnostic examinations } & 1164 & Overall & $2,832,902.0$ & $2433.8(1,615.8)$ & $176.1-11,254.8$ \\
\hline & 1160 & OCT & $1,125,541.5$ & $970.3(586.1)$ & 123.o-3198.3 \\
\hline & 66 & FA & 5754.7 & $87.2(106.0)$ & $65.4-915.6$ \\
\hline & 28 & ICG & 2594.0 & $92.6(22.7)$ & $86.5-172.9$ \\
\hline & 138 & Angio-OCT & $41,049.0$ & $297.5(307.5)$ & $136.8-2736.6$ \\
\hline & 153 & Autofluorescence & $11,377.1$ & $74.4(46.9)$ & $39.8-238.7$ \\
\hline & 652 & Retinography & $775,951.7$ & $1190.1(735.0)$ & $140.2-4486.1$ \\
\hline & 285 & Fundus $^{\mathrm{a}}$ & $36,823.0$ & $129.2(81.3)$ & $15.9-382.1$ \\
\hline & 860 & Fundus $^{\mathrm{b}}$ & $303,286.9$ & $352.7(239.7)$ & $53.1-1359.3$ \\
\hline & 1160 & VA & $404,347.1$ & $348.6(213.8)$ & $53.1-1359.3$ \\
\hline & 640 & Tonometry & $125,251.1$ & $195.7(160.4)$ & $53.1-1359.3$ \\
\hline & 3 & Genetic test & 182.9 & $61.0(0.0)$ & $61.0-61.0$ \\
\hline & 1 & Blood analysis & 116.9 & 116.9 (N.A.) & N.A \\
\hline & 2 & Visual field & 232.4 & $116.2(98.6)$ & $46.5-185.9$ \\
\hline & 2 & Ultrasonography & 394.0 & 197.0 (N.A.) & $197.0-197.0$ \\
\hline \multirow[t]{3}{*}{ Medical examinations } & $1145^{3}$ & Overall & $503,706.5$ & $439.9(217.2)$ & $0.0-1659.1$ \\
\hline & 1143 & Ophthalmology & $486,522.2$ & $425.7(204.6)$ & $77.5-1549.9$ \\
\hline & 99 & Emergency ${ }^{4}$ & $17,194.3$ & $173.6(95.9)$ & $139.7-698.6$ \\
\hline \multirow[t]{2}{*}{ Surgery } & 5 & Overall & $11,645.4$ & 2329.1 (N.A.) & $2329.1-2329.1$ \\
\hline & 5 & Vitrectomy & $11,645.4$ & 2329.1 (N.A.) & $2329.1-2329.1$ \\
\hline
\end{tabular}

${ }^{1}$ Costs have been updated for the year 2020

${ }^{2} 115$ patients received two anti-VEGF and 90 did not receive any

${ }^{3}$ Patients could have gone to both departments

${ }^{4}$ Only ophthalmology emergencies

${ }^{\mathrm{a}}$ Indirect ophthalmoscopy

${ }^{\mathrm{b}}$ Biomicroscopy 
Three patients had more than one AE. An overview of the different treatment-related AEs is shown in Table 4.

\section{Discussion}

This study was designed to assess the economic burden, in terms of direct health costs, of AMD in a patient population where the predominant treatment was anti-VEGF therapy.

Late-stage AMD may be divided into two different forms, namely the nonvascular subtype or dry AMD (geographic atrophy) and the neovascular subtype (NVAMD) or wet AMD, which is less frequent but responsible of approximately the $90 \%$ of blindness related to AMD [1, 2].

To our knowledge, information evaluating the economic burden of AMD in Spain, since the advent of anti-VEGF therapy as the standard of care, is very limited.

According to the results of this study, diagnostic tests and intravitreal anti-VEGF injections represented the items with the largest direct health costs.

Preserving population health requires work and money. Achieving it implies that National Health Systems should face unlimited demand with limited resources. That is why, health economics is exerting an influence on decision making at all levels of health care [24].

Demographic aging is leading to a substantial increase in the prevalence of age-related sight-impairing conditions and associated increases in their costs $[10,25,26]$. However, despite the relevance of this

Table 4 Incidence of treatment-related adverse events (AEs) in the study sample (1164 subjects; 6057 injections) during the study follow-up

\begin{tabular}{lc}
\hline Adverse event & Number (\%) \\
\hline Overall & $29(2.5)$ \\
Cataract & $12(1.0)$ \\
Elevated IOP & $11(0.9)$ \\
Endophthalmitis* & $6(0.099)$ \\
Retinal detachment & $1(0.1)$ \\
Other & $3(0.3)$ \\
\hline
\end{tabular}

*Per injection (sample 6057 injections) issue, to date, there has been little work evaluating the economic impact of AMD in a Spanish setting.

The average annual societal cost per bilateral NVAMD patient treated was estimated to be euro 5732 in Spain, direct vision-related medical costs accounted for $23-63 \%$ of the total cost [27]. When we update the prices by using the cost price index (CPI), it results in an increase of the $14.8 \%$ between January 2008 and July 2020 [28]. With this rate of variation, the updated costs of Cruess et al. [27] are €6,534.5. In our study, mean annual cost/per patient was slightly lower $(€ 4,627.6)$, but we did not consider direct nonmedical-related costs, like, for example, home healthcare and social services costs.

According to data of National Statistics Institute, there are about 9.27 million people $\geq 65$ years in Spain [29]. The prevalence of NVAMD in Europe, among subjects $\geq 65$ years, has been estimated to be $2.29 \%$ [27]. Based on this assumption, there are approximately 212,280 patients ( $\geq 65$ years) with NVAMD in Spain [29, 30]. Based on this estimation, the main direct health costs associated with NVAMD might suppose $€ 982.4$ million. On the other hand, the Spanish Eyes Epidemiological (SEE) Study estimated an overall prevalence of AMD of $3.4 \%$ among subjects $\geq 65$ years [12]. Assuming these figures, approximately 315,180 patients ( $\geq 65$ years) would have NVAMD in Spain, which suppose $€ 1458.5$ million. In summary, it is possible to estimate that the total direct health burden associated with NVAMD (main direct health costs per patient $\mathrm{x}$ estimated number of Spanish patients with NVAMD) would range between $€ 982.4$ million and $€ 1458.6$ million, which represents an $1.37-2.10 \%$ of Spanish total public health spending [31].

Although medical treatment of NVAMD experienced a significant advance due to the introduction of anti-VEGF agents, they have several drawbacks, including their high cost and the lack of efficiency.

Among patients included in the current study, $27.9 \%$ received treatment with bevacizumab, $28.2 \%$ with ranibizumab, and $53.8 \%$ with aflibercept. Although, when compared to Italy, the proportion of patients treated with bevacizumab was similar, the proportion of patients treated with ranibizumab and aflibercept was totally different [32]. While in the current study $53.8 \%$ of patients were treated with aflibercept, in Italy only $25.3 \%$ of patients received treatment with it. Similarly, $28.2 \%$ of patients 
received treatment with ranibizumab, while that proportion was $55.3 \%$ in Italy [32].

The cost differences between ranibizumab and aflibercept may be due to the fact that costing approach assumes vial splitting for aflibercept, but not ranibizumab. Although preloaded ranibizumab is usually the first option, in those cases that the ophthalmologist decides to use a vial, vial splitting, as performed with aflibercept, would be used for ranibizumab as well.

Despite anti-VEGF therapy has become the current standard of care for NVAMD [33], many patients do not respond adequately to this therapy or experience a slow loss of efficacy of anti-VEGF agents after repeated administration over time [34, 35].

Although new approaches for treating NVAMD have been proposed, as far as we know, there is no evidence about their cost or cost-effectiveness.

Regarding complications, the high incidence of endophthalmitis reported in the current study is noteworthy. On average, the incidence of endophthalmitis after intravitreal injections of anti-VEGF or corticosteroids is low [36-41]. It ranges between $0.00 \%$ [41] and $0.021 \%$ [36]. In our study, the incidence of endophthalmitis was $0.099 \%$ (95\% CI: $0.036-0.215 \%)$. Although the incidence of endophthalmitis was slightly greater than that reported in other studies, there is no any objective reason, with the exception of the small sample size, that might justify this finding.

It is important to acknowledge some limitations when interpreting these findings. Our study did not evaluate direct non-medical-related costs (e.g., home healthcare and social services), patient transportation, or other incidentals, to establish economic parameters. The study sample was limited to five Spanish Autonomous Communities, which may only reflect the reality of these regions. Nevertheless, the methodology could be easily replicated in other regions. Finally, it should be mentioned that mean cost per patient in the overall study sample was affected by the fact that 90 patients did not receive anti-VEGF therapy. Nevertheless, the mean cost per patient in eyes who underwent anti-VEGF therapy and those who did not was calculated, which solves this limitation.

\section{Conclusions}

NVAMD was associated with considerable healthcare costs. Diagnostic examinations, particularly OCT examinations, represented the largest cost item.

Additionally, anti-VEGF treatment represented a relevant burden for healthcare systems, due mainly to its high price, needs for repetitive administration, and frequent outpatient visits.

Further studies are needed to determine the role of future therapies, which may reduce the burden of current therapies but maintain high efficacy/safety profile, on the human and economic burden of AMD in Spain.

Acknowledgements Medical writing and Editorial assistant services have been provided by Ciencia y Deporte S.L. and covered by a Grant from Allergan. Support for this assistance was funded by Allergan, an AbbVie company.

Authors Contribution All authors met the ICMJE authorship criteria. All authors made substantial contributions to conception, design, analysis and interpretation of data, contributed to writing the article, provided critical revision of the manuscript, and approved the final version.

Funding The authors wish to acknowledge Allergan for their support with the medical writing. It should be noted that Allergan was not involved in the preparation of the manuscript nor did the company influence in any way the scientific conclusions reached. Editorial assistance in the preparation of this manuscript was provided by Antonio Martinez MD (Ciencia y Deporte S.L.). Support for this assistance was funded by Allergan, an AbbVie company.

Data availability The datasets used and/or analyzed during the current study are available from the corresponding author on reasonable request.

\section{Declarations}

Conflict of interest Dr Ruiz-Moreno has received a grant from Allergan during the conduct of the study. None of the coauthors have any conflict of interest to declare.

Consent to participate The local ethics committee waived the need for written informed consent of the participants.

Open Access This article is licensed under a Creative Commons Attribution 4.0 International License (https:// creativecommons.org/licenses/by/4.0/), which permits use, sharing, adaptation, distribution and reproduction in any medium or format, as long as you give appropriate credit to the original author(s) and the source, provide a link to the Creative Commons licence, and indicate if changes were made. The images or other third party material in this article are included in 
the article's Creative Commons licence, unless indicated otherwise in a credit line to the material. If material is not included in the article's Creative Commons licence and your intended use is not permitted by statutory regulation or exceeds the permitted use, you will need to obtain permission directly from the copyright holder. To view a copy of this licence, visit http://creativecommons.org/licenses/by/4.0/.

\section{References}

1. Cheung LK, Eaton A (2013) Age-related macular degeneration. Pharmacotherapy 33(8):838-855. https://doi.org/ 10.1002/phar.1264

2. Gheorghe A, Mahdi L, Musat O (2015) Age-related macular degeneration. Rom J Ophthalmol 59(2):74-77

3. Vingerling JR, Dielemans I, Hofman A, Grobbee DE, Hijmering M, Kramer CF et al (1995) The prevalence of age-related maculopathy in the Rotterdam Study. Ophthalmology 102:205-1011. https://doi.org/10.1016/s01616420(95)31034-2

4. Pascolini D, Mariotti SP (2012) Global estimates of visual impairment: 2010. Br J Ophthalmol 96(5):614-618. https:// doi.org/10.1136/bjophthalmol-2011-300539

5. Wong WL, Su X, Li X, Cheung CM, Klein R, Cheng CY et al (2014) Global prevalence of age-related macular degeneration and disease burden projection for 2020 and 2040: a systematic review and meta-analysis. Lancet Glob Health 2(2):e106-116. https://doi.org/10.1016/S2214109X(13)70145-1

6. Korb CA, Kottler UB, Wolfram C, Hoehn R, Schulz A, Zwiener I et al (2014) Prevalence of age-related macular degeneration in a large European cohort: results from the population-based Gutenberg Health Study. Graefes Arch Clin Exp Ophthalmol 252(9):1403-1411. https://doi.org/10. 1007/s00417-014-2591-9

7. Zapata MA, Arcos G, Fonollosa A, Abraldes M, Oleñik A, Gutierrez E et al (2017) Telemedicine for a general screening of retinal disease using nonmydriatic fundus cameras in optometry centers: three-year results. Telemed J E Health 23(1):30-36. https://doi.org/10.1089/tmj.2016. 0020

8. García-Layana A, Cabrera-López F, García-Arumí J, AriasBarquet L, Ruiz-Moreno JM (2017) Early and intermediate age-related macular degeneration: update and clinical review. Clin Interv Aging 12:1579-1587. https://doi.org/10. 2147/CIA.S142685

9. Klein R, Klein BEK, Linton KLP (2020) Prevalence of agerelated maculopathy: the beaver dam eye study. Ophthalmology 127(4S):S122-S132. https://doi.org/10.1016/j. ophtha.2020.01.033

10. Pennington KL, DeAngelis MM (2016) Epidemiology of age-related macular degeneration (AMD): associations with cardiovascular disease phenotypes and lipid factors. Eye Vis (Lond) 3:34. https://doi.org/10.1186/s40662-016-0063-5

11. Ferris FL, Wilkinson CP, Bird A, Chakravarthy U, Chew E, Csaky K, Beckman Initiative for Macular Research Classification Committee et al (2013) Clinical classification of age-related macular degeneration. Ophthalmology 120(4):844-851. https://doi.org/10.1016/j.ophtha.2012.10. 036

12. Spanish Eyes Epidemiological (SEE) Study Group (2011) Prevalence of age-related macular degeneration in Spain. Br J Ophthalmol 95(7):931-936. https://doi.org/10.1136/bjo. 2010.187773

13. Jager RD, Mieler WF, Miller JW (2008) Age-related macular degeneration. N Engl J Med 358(24):2606-2617

14. Brown DM, Kaiser PK, Michels M, Soubrane G, Heier JS, Kim RY et al (2006) ANCHOR Study Group. Ranibizumab versus verteporfin for neovascular age-related macular degeneration. N Engl J Med 355(14):1432-1444. https:// doi.org/10.1056/NEJMoa062655

15. Rosenfeld PJ, Brown DM, Heier JS, Boyer DS, Kaiser PK, Chung CY et al (2006) MARINA Study Group Ranibizumab for neovascular age-related macular degeneration. N Engl J Med 355(14):1419-1431. https://doi.org/10.1056/ NEJMoa054481

16. Kaiser PK, Blodi BA, Shapiro H, Acharya NR, MARINA Study Group (2007) Angiographic and optical coherence tomographic results of the MARINA study of ranibizumab in neovascular age-related macular degeneration. Ophthalmology 114(10):1868-1875. https://doi.org/10.1016/j. ophtha.2007.04.030

17. Carrasco J, Pietsch GA, Nicolas MP, Koerber C, Bennison C, Yoon J (2020) Real-world effectiveness and real-world cost-effectiveness of intravitreal aflibercept and intravitreal ranibizumab in neovascular age-related macular degeneration: systematic review and meta-analysis of real-world studies. Adv Ther 37(1):300-315. https://doi.org/10.1007/ s12325-019-01147-6

18. van Asten F, Michels CTJ, Hoyng CB, van der Wilt GJ, Klevering BJ, Rovers MM et al (2018) The cost-effectiveness of bevacizumab, ranibizumab and aflibercept for the treatment of age-related macular degeneration-a cost-effectiveness analysis from a societal perspective. PLoS ONE 13(5):e0197670. https://doi.org/10.1371/journal.pone. 0197670

19. OECD/European Observatory on Health Systems sand Policies (2017), Spain: Country Health Profile 2017, State of Health in the EU, OECD Publishing, Paris/European Observatory on Health Systems and Policies, Brussels. Available in https://doi.org/10.1787/9789264283565-en. Last accessed March 6, 2021

20. Authors no listed. Spanish database of healthcare costs: eSalud [Internet]. Barcelona: Oblikue Consulting, S.L. 2007. Available in: http://www.oblikue.com/bddcostes/ Last accessed March 6, 2021

21. Authors no listed. Bevacizumab. Summary of product characteristics. Available in: https://www.ema.europa.eu/ en/documents/product-information/avastin-epar-productinformation_en.pdf Last accessed March 6, 2021

22. Authors no listed. Ranibizumab. Summary of product characteristics. Available in: https://www.ema.europa.eu/ en/documents/product-information/lucentis-epar-productinformation_en.pdf Last accessed March 6, 2021

23. Authors no listed. Aflibercept. Summary of product characteristics. Available in: https://www.ema.europa.eu/en/ documents/product-information/eylea-epar-productinformation_en.pdf Last accessed March 6, 2021 
24. Kernick DP (2003) Introduction to health economics for the medical practitioner. Postgrad Med J 79(929):147-150. https://doi.org/10.1136/pmj.79.929.147

25. Taylor HR, Pezzullo ML, Keeffe JE (2006) The economic impact and cost of visual impairment in Australia. Br J Ophthalmol 90(3):272-275. https://doi.org/10.1136/bjo. 2005.080986

26. Pezzullo L, Streatfeild J, Simkiss P, Shickle D (2018) The economic impact of sight loss and blindness in the UK adult population. BMC Health Serv Res 18(1):63. https://doi.org/ 10.1186/s12913-018-2836-0

27. Cruess AF, Zlateva G, Xu X, Soubrane G, Pauleikhoff D, Lotery A et al (2008) Economic burden of bilateral neovascular age-related macular degeneration: multi-country observational study. Pharmacoeconomics 26(1):57-73. https://doi.org/10.2165/00019053-200826010-00006

28. ESCPI2013 [Spain - Instituto Nacional de Estadistica (INE)]. Available in https://www.ine.es/calcula/calcula. do;jsessionid=78F41704406F099CA1055CDF51947999. calcula01 Last accessed March 7, 2021

29. Autores no listados. Instituto nacional de Estadística. Data of Spanish Population. Available in: https://www.ine.es/ dyngs/INEbase/es/operacion.htm?c=Estadistica_C\&cid= $1254736176951 \&$ menu $=$ ultiDatos\&idp $=1254735572981$ Last accessed March 7, 2021

30. Augood CA, Vingerling JR, de Jong PT, Chakravarthy U, Seland J, Soubrane G et al (2006) Prevalence of age-related maculopathy in older Europeans: the European Eye Study (EUREYE). Arch Ophthalmol 124(4):529-535. https://doi. org/10.1001/archopht.124.4.529

31. Rodríguez-Blas MC. Estadística de Gasto Sanitario Público 2018. Available in: https://www.mscbs.gob.es/estadEstudios/ estadisticas/docs/EGSP2008/egspPrincipalesResultados.pdf Last accessed March 7, 2021

32. Authors not listed. L'uso dei farmaci in Italia-Rapporto OsMed 2018. Available in: https://www.aifa.gov.it/web/ guest/-/rapporto-osmed-20-1 Last accessed March 7, 2021

33. Schmidt-Erfurth U, Chong V, Loewenstein A, Larsen M, Souied E, Schlingemann R et al (2014) European Society of Retina Specialists. Guidelines for the management of neovascular age-related macular degeneration by the European Society of Retina Specialists (EURETINA). Br J Ophthalmol 98(9):1144-1167. https://doi.org/10.1136/ bjophthalmol-2014-305702

34. Broadhead GK, Hong T, Chang AA (2014) Treating the untreatable patient: current options for the management of treatment-resistant neovascular age-related macular degeneration. Acta Ophthalmol 92(8):713-723. https://doi. org/10.1111/aos.12463

35. Yang S, Zhao J, Sun X (2016) Resistance to anti-VEGF therapy in neovascular age- related macular degeneration: a comprehensive review. Drug Des Devel Ther 10:1857-1867. https://doi.org/10.2147/DDDT.S97653

36. Dossarps D, Bron AM, Koehrer P, Aho-Glélé LS, CreuzotGarcher C, FRCR net (FRenCh Retina specialists net) (2015) Endophthalmitis after intravitreal injections: incidence, presentation, management, and visual outcome. Am J Ophthalmol 160(1):17-25.e1. https://doi.org/10.1016/j. ajo.2015.04.013

37. Stem MS, Todorich B, Yonekawa Y, Capone A Jr, Williams GA, Ruby AJ (2017) Incidence and visual outcomes of culture-proven endophthalmitis following dexamethasone intravitreal implant. JAMA Ophthalmol 135(4):379-382. https://doi.org/10.1001/jamaophthalmol.2016.5883

38. Rajesh B, Zarranz-Ventura J, Fung AT, Busch C, Sahoo NK, Rodriguez-Valdes PJ, International Ozurdex Study Group et al (2020) Safety of 6000 intravitreal dexamethasone implants. Br J Ophthalmol 104(1):39-46. https://doi. org/10.1136/bjophthalmol-2019-313991

39. VanderBeek BL, Bonaffini SG, Ma L (2015) The association between intravitreal steroids and post-injection endophthalmitis rates. Ophthalmology 122(11):23112315.e1. https://doi.org/10.1016/j.ophtha.2015.07.005

40. Freiberg FJ, Brynskov T, Munk MR, Sørensen TL, Wolf S, Wirth MA et al (2017) Low endophthalmitis rates after intravitreal anti-vascular endothelial growth factor injections in an operation room: a retrospective multicenter study. Retina 37(12):2341-2346. https://doi.org/10.1097/ IAE.0000000000001488

41. Cidad-Betegón MDP, Armadá-Maresca F, Amorena-Santesteban G, Coca-Robinot J, D'Anna-Mardero O, de la Rosa-Pérez I et al (2020) Can the dexamethasone intravitreal implant Ozurdex be safely administered in an out-ofoperating room setting? J Drug Assess 9(1):66-71. https:// doi.org/10.1080/21556660.2020.1742723

Publisher's Note Springer Nature remains neutral with regard to jurisdictional claims in published maps and institutional affiliations. 